\title{
Amorphous Al-Ti Powders Prepared by Mechanical Alloying and Consolidated by Electrical Resistance Sintering
}

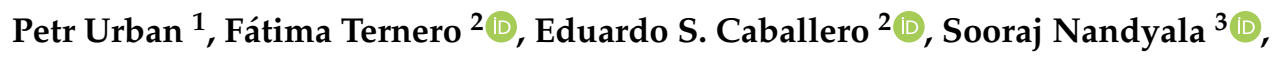 \\ Juan Manuel Montes ${ }^{2}(D)$ and Francisco G. Cuevas $4, *(D)$ \\ 1 Department of Materials and Transportation Engineering and Science, Escuela Politécnica Superior, \\ Universidad de Sevilla, 41011 Sevilla, Spain; purban@us.es \\ 2 Department of Materials and Transportation Engineering and Science, Escuela Técnica Superior de \\ Ingeniería, Universidad de Sevilla, 41092 Sevilla, Spain; fternero@us.es (F.T.); esanchez3@us.es (E.S.C.); \\ jmontes@us.es (J.M.M.) \\ 3 School of Metallurgy and Materials, College of Engineering and Physical Sciences, University of \\ Birmingham, Birmingham B15 2TT, UK; s.h.nandyala@bham.ac.uk \\ 4 Department of Chemical Engineering, Physical Chemistry and Materials Science, Escuela Técnica Superior \\ de Ingeniería, Universidad de Huelva, 21071 Huelva, Spain \\ * Correspondence: fgcuevas@dqcm.uhu.es; Tel.: +34-959-217-448
}

Received: 5 October 2019; Accepted: 22 October 2019; Published: 24 October 2019

\begin{abstract}
A novel processing method for amorphous $\mathrm{Al}_{50} \mathrm{Ti}_{50}$ alloy, obtained by mechanical alloying and subsequently consolidated by electrical resistance sintering, has been investigated. The characterisation of the powders and the confirmation of the presence of amorphous phase have been carried out by laser diffraction, scanning electron microscopy, X-ray diffraction, differential scanning calorimetry and transmission electron microscopy. The amorphous $\mathrm{Al}_{50} \mathrm{Ti}_{50}$ powders, milled for $75 \mathrm{~h}$, have a high hardness and small plastic deformation capacity, not being possible to achieve green compacts for conventional sintering. Moreover, conventional sintering takes a long time, being not possible to avoid crystallisation. Amorphous powders have been consolidated by electrical resistance sintering. Electrically sintered compacts with different current intensities (7-8 kA) and processing times $(0.8-1.6 \mathrm{~s})$ show a porosity between 16.5 and $20 \%$. The highest Vickers hardness of $662 \mathrm{HV}$ is reached in the centre of an electrically sintered compact with $8 \mathrm{kA}$ and $1.2 \mathrm{~s}$ from amorphous $\mathrm{Al}_{50} \mathrm{Ti}_{50}$ powder. The hardness results are compared with the values found in the literature.
\end{abstract}

Keywords: electrical resistance sintering; amorphisation; crystallisation; mechanical alloying; Al-Ti powders; porosity; hardness

\section{Introduction}

Al-Ti crystalline alloys are very attractive low-density materials with excellent properties at high temperatures [1]. Titanium aluminides are used for engine and airframe applications, mostly in the aerospace industry. The development of Al-Ti alloys began about 1970; however the alloys have only been used in these applications since about 2000 [2].

In general, the transformation of the crystalline phase of metallic materials to an amorphous phase can improve properties such as corrosion resistance [3], hardness [4] or mechanical strength [5]. An ideal method to obtain the amorphous phase in significant quantities is mechanical alloying.

Mechanical alloying (MA) is a peculiar grinding process that employs a high-energy ball mill in order to produce a composite metal powder with a controlled microstructure. This happens through repeated welding and fracturing of a mixture of metallic (and non-metallic) powders by the action of 
the mill balls. To achieve the desired amorphous phase, the optimisation of a considerable number of variables is required. Some of the important parameters affecting the amorphisation of the powders, without being completely independent, are the type of mill, the container and the milling balls, the rotating speed (intensity), the milling time and temperature. Moreover, the ratio of the weight of the balls and weight of the powder (RBP), the milling atmosphere, the process control agent (PCA), etc. also affect the final microstructure.

The obtained amorphous structure is thermodynamically instable, and in order to preserve the amorphous character of the alloyed powder, it is very convenient to have a fast consolidation technique in relation to diffusive processes, such as the known as Field Assisted Sintering Techniques (FAST) [6,7]. These techniques take advantage of the Joule heat generated by the passage of an electric current through the powder mass. One of these techniques, Spark Plasma Sintering (SPS), has recently been applied to mechanically alloyed $\mathrm{Al}_{86} \mathrm{Ni}_{8} \mathrm{Y}_{6}$ amorphous powders $[8,9]$ reaching temperatures of up to $400{ }^{\circ} \mathrm{C}$ for a relatively long time in the order of minutes. However, other techniques such as Electrical Resistance Sintering (ERS) need a much shorter heating period.

The sintering of crystalline metal powders using electricity has been known for several decades. Bloxam [10] was the first who reported and patented an electrical sintering method by applying a high intensity current through the metallic powder (electrical conductor); later, Weintraub and Rush [11] combined electric current with pressure, and Taylor [12] added the use of capacitors to eliminate the oxides covering the metal powders. These techniques are a type of hot pressing in which the powder itself generates heat due to the Joule effect, and are called "electrical resistance sintering under pressure". However, these methods are still today of great interest [13,14], coexisting with the traditional powder metallurgy (PM) route of cold pressing and furnace sintering. The main advantages are the achievement of very high densities with moderate or low pressures (around $100 \mathrm{MPa}$ ), the need of extraordinarily short sintering times (about one second) and the option of sintering in air. Its main disadvantage arises from operational difficulties, and the fact of not achieving a homogeneous distribution of temperature and densification in the powder mass.

In this work, amorphous $\mathrm{Al}_{50} \mathrm{Ti}_{50}$ alloy is prepared by $\mathrm{MA}$ and the effect of different parameters of the ERS process on porosity, microstructure, formation of intermetallic compounds, kinetics of devitrification and hardening are analysed.

\section{Materials and Methods}

Pure elemental powders of aluminum AS61 (Eckart-Werke, Eckart, Germany, purity $>99.5 \%$ ) and titanium Se-Jong 4 (Se-Jong Materials, Incheon, South Korea, purity > 99.5\%) were mixed to give the desired compositions of $\mathrm{Al}_{50} \mathrm{Ti}_{50}$. The manufacturer's chemical analysis for pure aluminum and pure titanium powders is given in Tables 1 and 2, respectively.

Table 1. Chemical analysis of Al AS61 powder as indicated by Eckart-Werke.

\begin{tabular}{cccccccc}
\hline Element & Al & Si & Fe & Zn & Cu & Ti & Others \\
\hline wt. $\%$ & $>99.5$ & $<0.250$ & $<0.350$ & $<0.050$ & $<0.020$ & $<0.020$ & $<0.500$ \\
\hline
\end{tabular}

Table 2. Chemical analysis of Ti Se-Jong 4 powder as indicated by Se-Jong Materials.

\begin{tabular}{cccccccc}
\hline Element & Ti & $\mathbf{O}$ & $\mathbf{N}$ & $\mathbf{H}$ & $\mathbf{F e}$ & Si & Others \\
\hline wt. \% & $>99.5$ & $<0.440$ & $<0.014$ & $<0.010$ & $<0.040$ & $<0.080$ & $\begin{array}{c}<0.005 \mathrm{Mg} \\
<0.006 \mathrm{Mn}\end{array}$ \\
\hline
\end{tabular}

The mixture of $72 \mathrm{~g}$ of $\mathrm{Al}_{50} \mathrm{Ti}_{50}$ powder was placed in a sealed cylindrical 304 stainless steel vial, together with 304 stainless steel balls and $1.5 \mathrm{wt}$. \% of ethylene bis-stearamide (EBS) wax $\left(\mathrm{C}_{38} \mathrm{H}_{76} \mathrm{~N}_{2} \mathrm{O}_{2}\right)$, as shown in Figure 1. The wax (PCA) function is to equilibrate the particles welding and rupture processes. Powders were alloyed up to $75 \mathrm{~h}$ in a high-energy attritor ball mill under a purified argon 
atmosphere to minimize contamination (oxygen and nitrogen from air). The RBP was fixed to 50:1, the rotor speed was $500 \mathrm{rpm}$, and the dry ball mill was carried out at room temperature. The MA experiment was interrupted at desired intervals and small amounts of the alloyed mix were taken out from the vial for analysis.

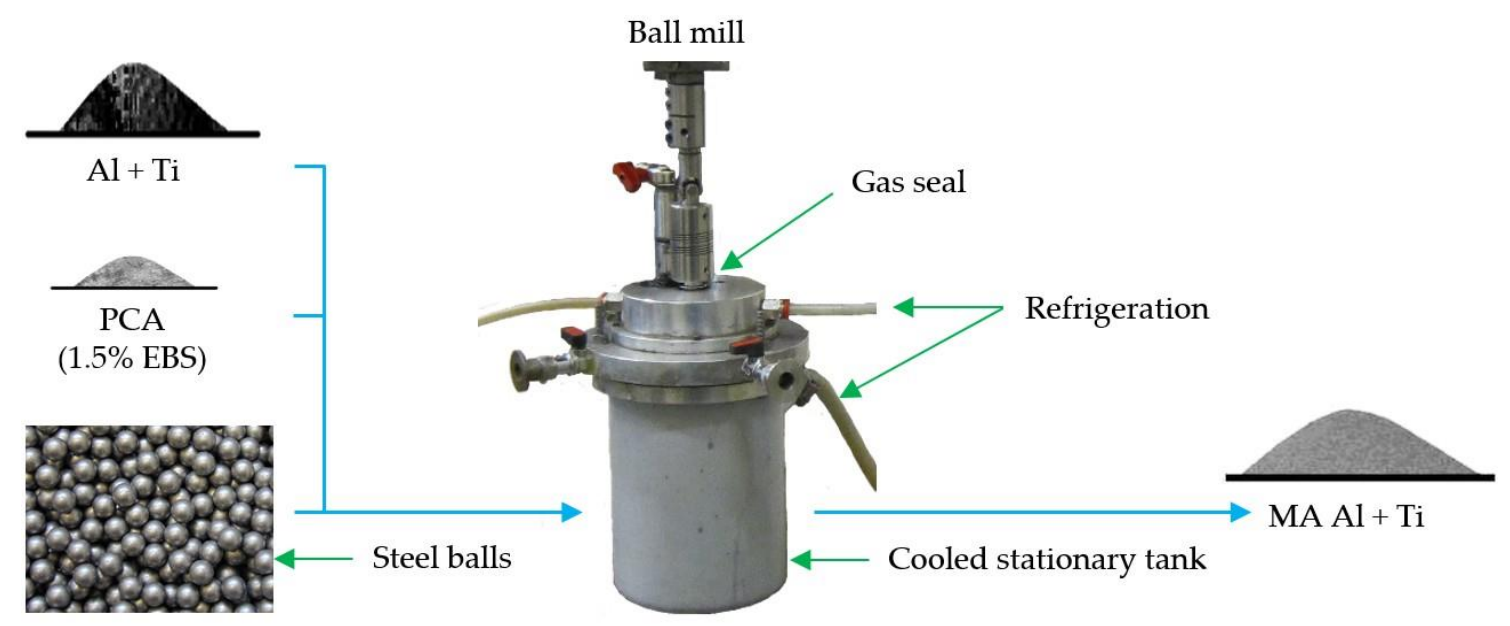

Figure 1. Scheme of the amorphisation procedure by mechanical alloying.

Size distribution and granulometric curves of the powders alloyed for different times were obtained by laser diffraction (Mastersizer 2000, Malvern Instruments, Malvern, UK). The structure and amorphisation progress of the ball milled powders were characterized by X-ray diffraction (XRD, D500, Siemens, Munich, Germany) with CuK $\alpha$ radiation, scanning electron microscopy (SEM, XL 30, Philips, Amsterdam, The Netherlands) and transmission electron microscopy (TEM, CM-200, Philips, Amsterdam, The Netherlands). The crystallisation process was followed by differential scanning calorimeter (DSC, Q100, TA Instruments, New Castle, DE, USA) under an argon gas flow. All the DSC results were obtained with heating rates of $40{ }^{\circ} \mathrm{C} / \mathrm{min}$ up to a maximum temperature of $600{ }^{\circ} \mathrm{C}$.

For the ERS process a resistance welding machine has been used (Serra Soldadura S.A., Barcelona, Spain), which provides the necessary electrical (high intensity and low voltage) and mechanical (load for compression) requirements. This adapted equipment produces the current with a one-phase transformer of $100 \mathrm{kVA}$, and the uniaxial load with a pneumatic cylinder reaching up to $14 \mathrm{kN}$. Moreover, the direct current intensity during the process is electronically controlled, and follow-up sensors record the outstanding parameters as the mobile punch displacement, the load and the effective voltage and current intensity.

Once milled, powders were processed to obtain a bulk material. The $12 \mathrm{~mm}$ in diameter ceramic die (Figure 2) was confined by a metallic hoop. The outlets of the die were closed with water cooled electrodes of temperature resistant copper $(98.9 \% \mathrm{Cu}-1 \% \mathrm{Cr}-0.1 \% \mathrm{Zr})$, and electro-erosion resistant wafers $(75.3 \% \mathrm{~W}-24.6 \% \mathrm{Cu})$ in direct contact with the powder. The amorphous powders $(2 \mathrm{~g})$ were placed between the wafers for sintering. Due to their low thermal conductivity, the wafers dump the heat flow from the powder mass to the electrodes.

Powders were consolidated with a compaction pressure of $80 \mathrm{MPa}$ and only one electric pulse for each specimen. Several current intensities (7.0, 7.5 and $8.0 \mathrm{kA}$ ) and current passing times (40 to 80 cycles, with 50 cycles $=1.0 \mathrm{~s}$ ) were tested.

Hardness tests and light micrographs were carried out on diametrical planes of the cylindrical compacts mounted in Bakelite resin. Hardness measurements distribution in the diametrical plane is shown in Figure 3. (Indentations were carried out in different positions due to the non-uniform porosity distribution, coming from the temperature gradient generated during consolidation). Indentations were carried out in the center $\left(\mathrm{HV}_{\mathrm{c}}\right)$, in the outer layer near the surface $\left(\mathrm{HV}_{\mathrm{o}}\right)$ and in the inner area 
$\left(\mathrm{HV}_{\mathrm{i}}\right)$ of the compact. The hardness results were compared with the values of other investigations using different sintering techniques.

The structure and crystallisation progress of the compacts consolidated by ERS were characterized by XRD.

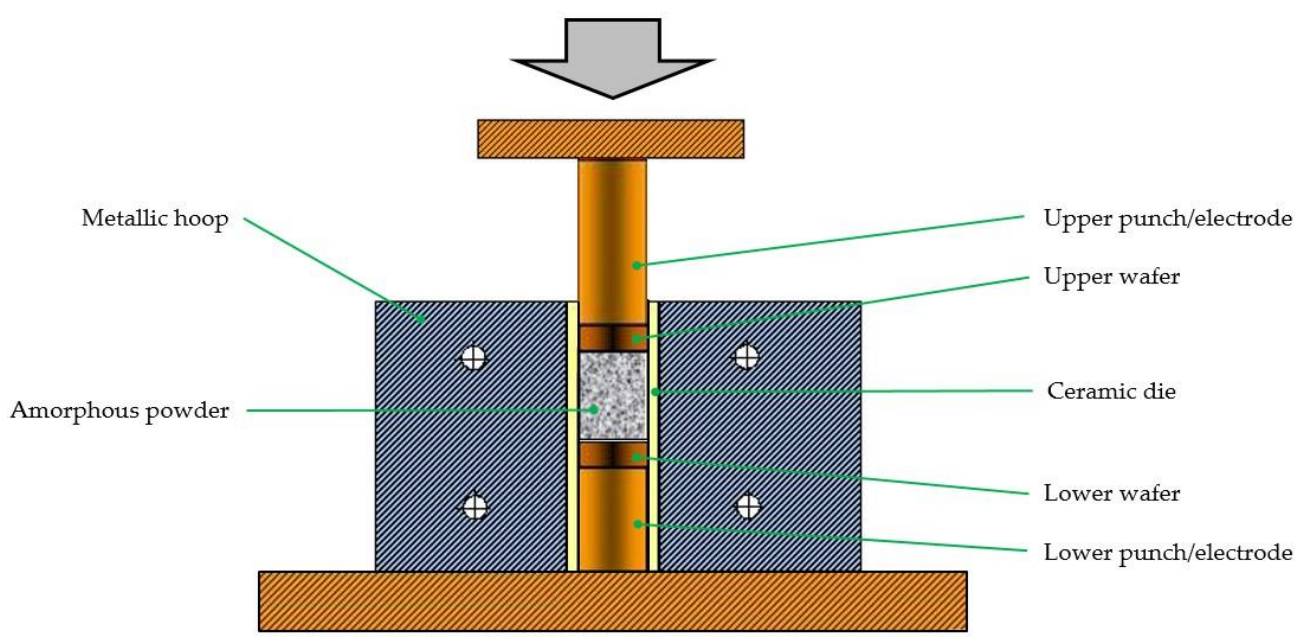

Figure 2. Scheme of the die, electrodes and powders in the ERS experiments. The upper punch/electrode and upper wafer are the only parts with movement allowed.

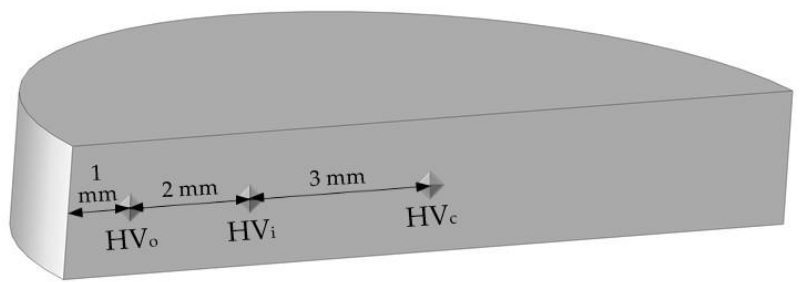

Figure 3. Positions of hardness indentations on a diametrical section of the cut specimen. Hardness in the other half is known because of the compact symmetry.

\section{Results}

\subsection{Amorphisation}

In the first part of the investigation, amorphous and/or nanocrystalline powders of the Al-Ti alloy are prepared by MA. The characterisation of the powders is done for different milling times. Laser diffraction measures particles size, SEM reveals morphology and confirms particle sizes. XRD indicates whether an amorphous and/or nanocrystalline phase is present and identifies the different crystalline phases. DSC shows the crystallisation temperature of the amorphous phase and TEM identifies amorphous, nanocrystalline and/or crystalline phases.

\subsubsection{Laser Diffraction}

At the beginning of the milling process, aluminium powder has an average particle size $d(0.5)$ of about $71.2 \mu \mathrm{m}$, and titanium powder of about $29.6 \mu \mathrm{m}$. As shown in Figure 4, the mixture of the two pure metals, in the 50/50 atomic ratio, results in an average particle size of about $41.3 \mu \mathrm{m}$.

During the first hours of milling, when fracture processes predominate, the average particle size decreases considerably, reaching about $18.5 \mu \mathrm{m}$ for $5 \mathrm{~h}$. Between 5 and $25 \mathrm{~h}$, the particle size remains stable without significant changes. However, going further of $25 \mathrm{~h}$ of milling, the dislocations density in the powder increases considerably, hardening it enough to make particle size to decrease to minimum values. Finally, it remains stable up to $75 \mathrm{~h}$, with $\mathrm{d}(0.5)$ values for 50 and $75 \mathrm{~h}$ of 10.4 and $8.6 \mu \mathrm{m}$, respectively. 


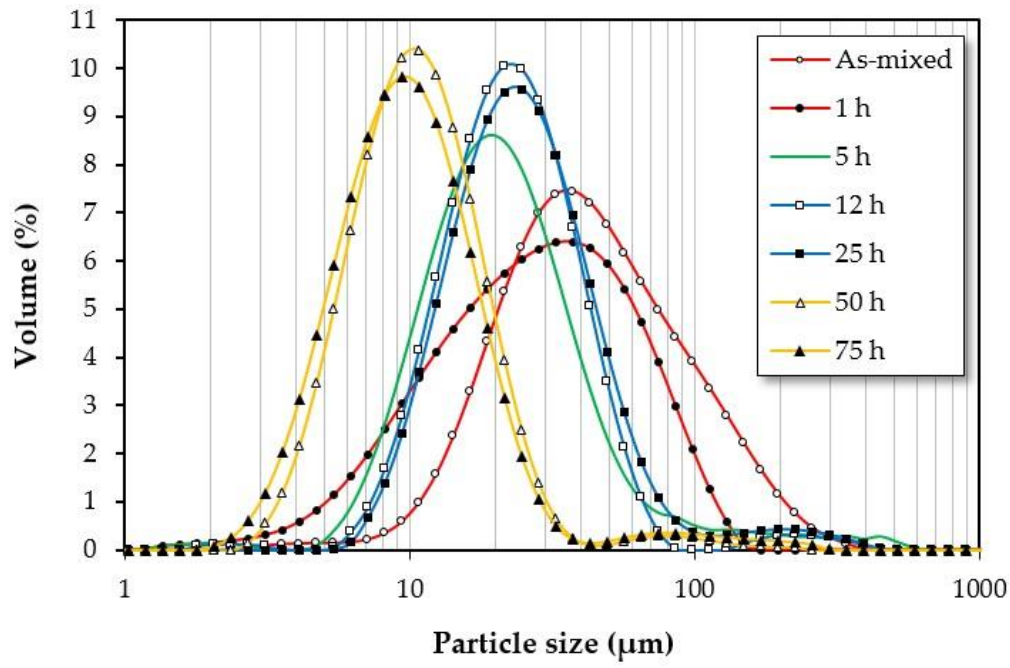

Figure 4. Granulometric curves of $\mathrm{Al}_{50} \mathrm{Ti}_{50}$ mixture and MA powders for different milling times.

\subsubsection{Scanning Electron Microscopy}

Figure 5a shows the mixed powders prior to ball milling, with irregular shaped large particles of aluminium and smaller and more equiaxial ones of titanium. In the initial phase of milling (up to $1 \mathrm{~h}$ ), the powder particles of $\mathrm{Al}$ and $\mathrm{Ti}$ are flattened and fragmented by ball-powder-ball collisions. After this time, particles of $\mathrm{Al}$ and Ti can still be distinguished with irregular shapes. After $5 \mathrm{~h}$ (Figure 5b), particles are more round and reach a quite small particle size of about $20 \mu \mathrm{m}$. The homogenisation by solid solution results clear. Between 5 and $12 \mathrm{~h}$, the particles have a very irregular rounded shape (Figure $5 \mathrm{c})$. When milling continues $(25-75 \mathrm{~h})$, particles are refined to about $10 \mu \mathrm{m}$, showing an almost spherical shape (Figure 5d).

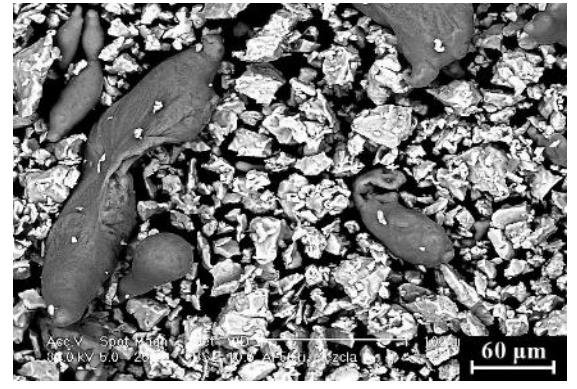

(a)

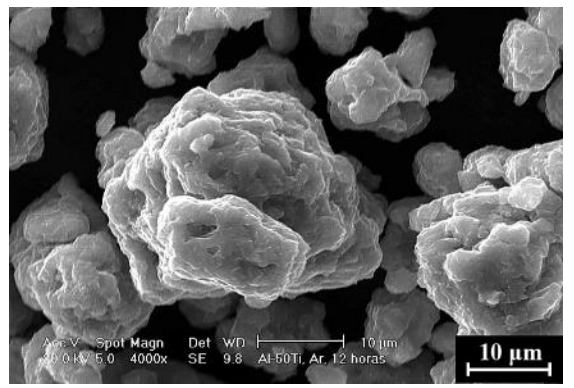

(c)

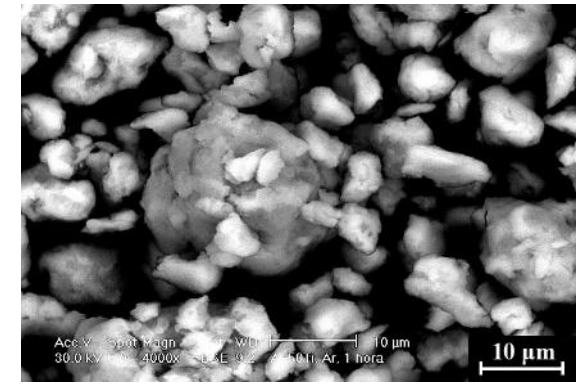

(b)

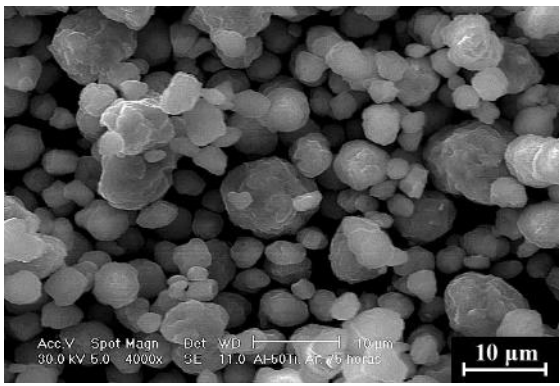

(d)

Figure 5. SEM micrographs of (a) the $\mathrm{Al}$ and $\mathrm{Ti}$ powders mixture, and the $\mathrm{Al}_{50} \mathrm{Ti}_{50}$ alloy milled for (b) 5, (c) 12 and (d) $75 \mathrm{~h}$. 


\subsubsection{X-ray Diffraction}

The initial study of the milled powders has been completed by XRD analysis (Figure 6). It is observed that for the first $5 \mathrm{~h}$ of milling, the intensity of the diffraction peaks of $\mathrm{Al}$ and Ti decreases as time increases. At the same time, the width of the peaks increases considerably as a result of the decrease in crystallite size. After $12 \mathrm{~h}$ of milling, the formation of a nanocrystalline/amorphous phase begins by atomic diffusion between $\mathrm{Al}$ and Ti. Thus, after $25 \mathrm{~h}$, independent peaks of $\mathrm{Al}$ and Ti cannot at all be observed and a characteristic wide peak of the amorphous phases appears with the maximum around $2 \Theta=39^{\circ}$. The percentage of amorphous phase increases with milling time, as evidenced by the widening of the halo.

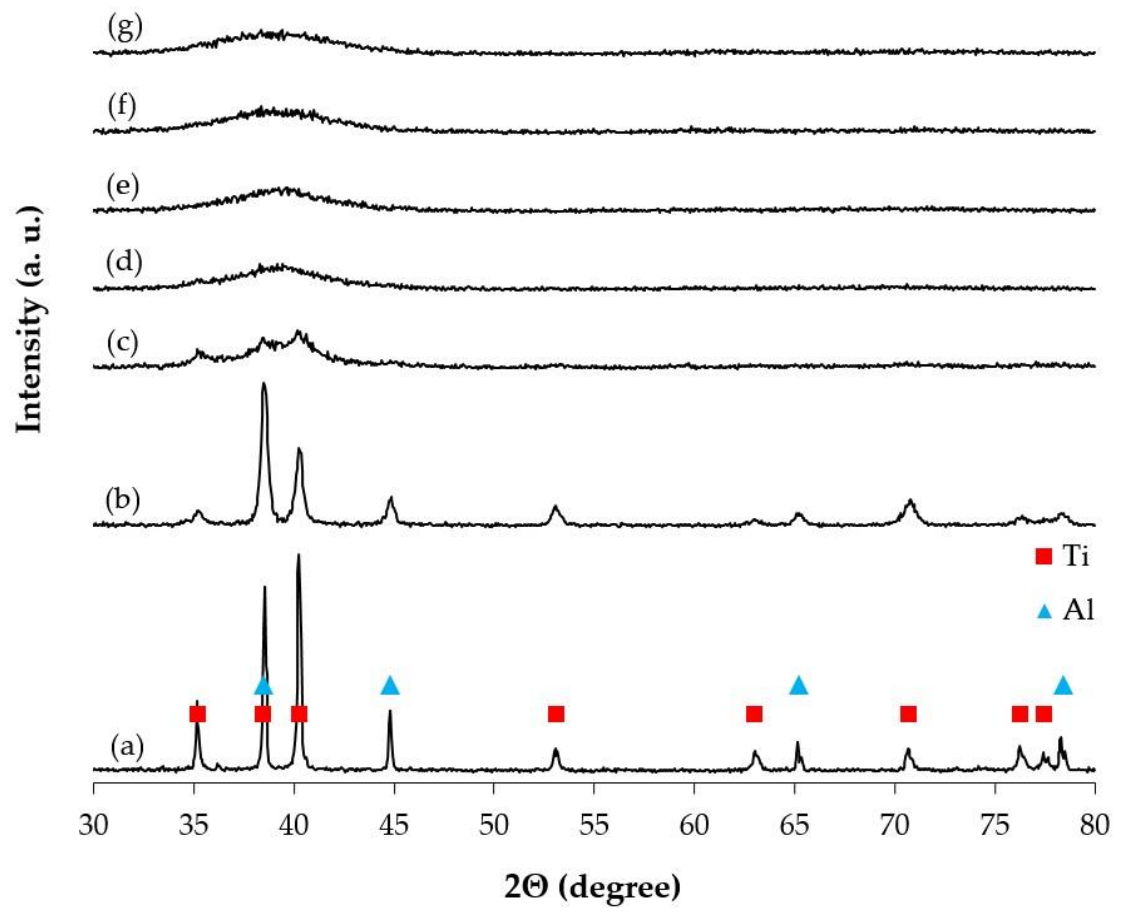

Figure 6. XRD patterns of (a) the Al and Ti powders mixture, and powders milled for (b) 1, (c) 5, (d) 12,

(e) 25 , (f) 50 and (g) $75 \mathrm{~h}$.

\subsubsection{Differential Scanning Calorimetry}

Amorphisation can also be verified by using DSC (Figure 7). For the powder milled for 12 and $25 \mathrm{~h}$, the appearance of an exothermic peak from $500{ }^{\circ} \mathrm{C}$ is observed, probably corresponding to the nanocrystals growth, and partial crystallisation of the amorphous phase formed during MA. After $50 \mathrm{~h}$, with a powder completely amorphous, there is a change in the shape of the curves obtained. An endothermic peak appears at about $400-550{ }^{\circ} \mathrm{C}$, possibly reflecting the heat flow anomaly characteristic of the glass transition (difficult to find for lower milling times because of the lower amount of amorphous phase). This endothermic peak could hide the exothermic peak corresponding to the crystallisation of the amorphous phase, or maybe crystallization is retarded to higher temperatures, forming titanium aluminides ( $\mathrm{AlTi}, \mathrm{Al}_{3} \mathrm{Ti}$ and $\left.\mathrm{AlTi}_{3}\right)$, which again must take place above $500{ }^{\circ} \mathrm{C}$. According to these results, in order to maintain the amorphous structure these powders could have a maximum temperature for consolidation, using conventional techniques, bellow $500{ }^{\circ} \mathrm{C}$.

\subsubsection{Transmission Electron Microscopy}

In order to confirm the presence of the amorphous phase, TEM of milled powders for 5, 25 and $75 \mathrm{~h}$ is shown in Figure 8. A crystalline/nanocrystalline structure can be found for $5 \mathrm{~h}$ of milling. After 
$25 \mathrm{~h}$ of milling possible amorphous zones can be found in the sample together with a nanocrystalline structure. However, after $75 \mathrm{~h}$ of milling, the crystalline phase has totally disappeared of the material.

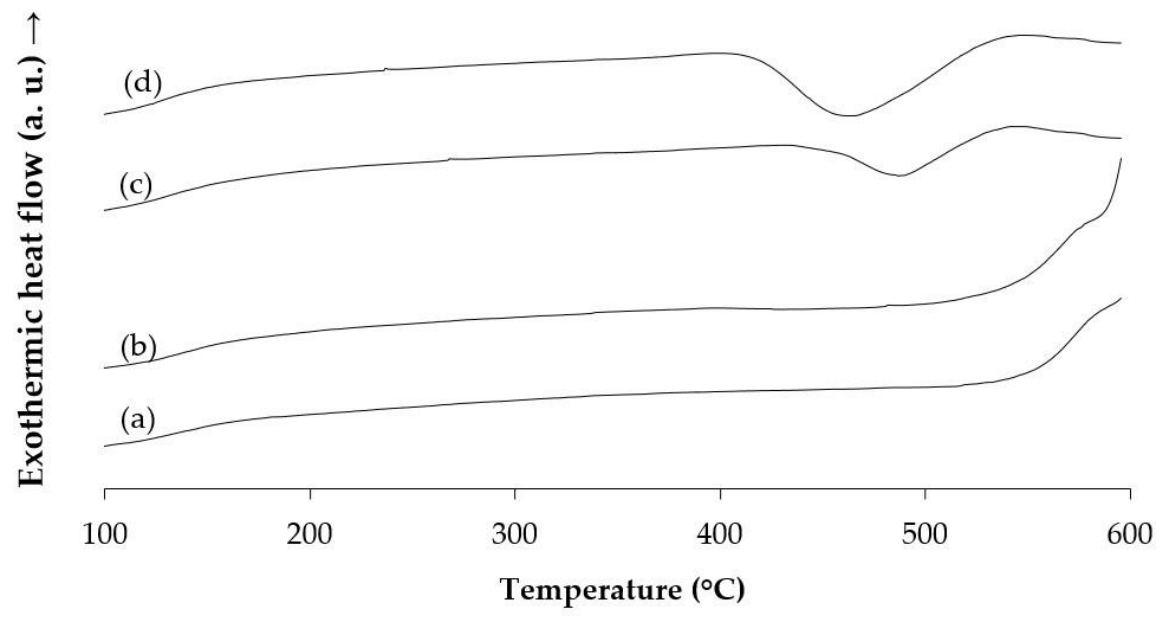

Figure 7. DSC of powders milled for (a) 12, (b) 25, (c) 50 and (d) $75 \mathrm{~h}$.

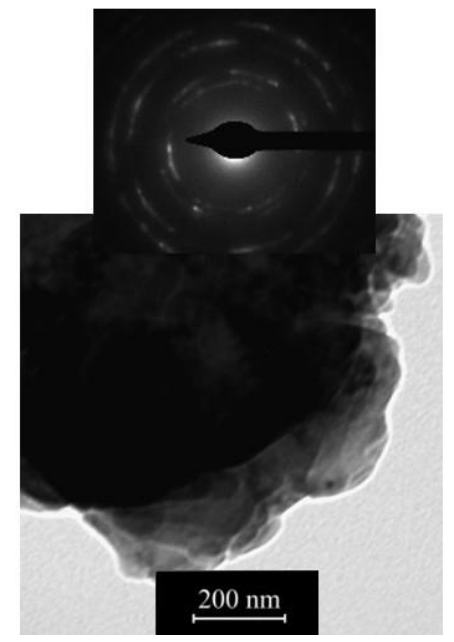

(a)

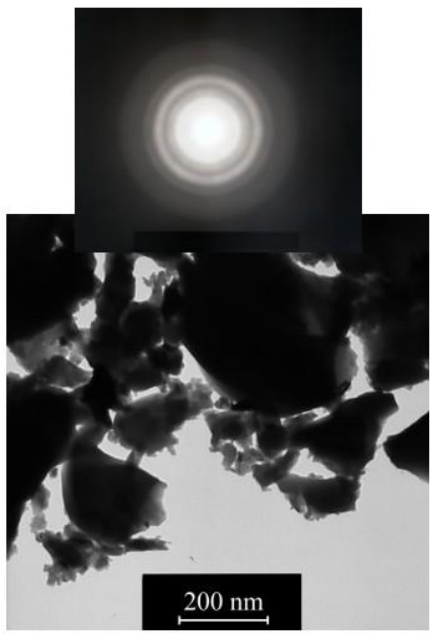

(b)

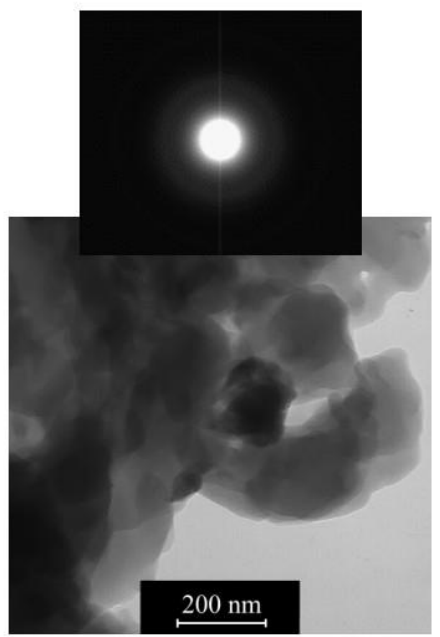

(c)

Figure 8. TEM micrographs and diffraction patterns of the $\mathrm{Al}_{50} \mathrm{Ti}_{50}$ alloy milled for (a) 5, (b) 25 and (c) $75 \mathrm{~h}$, showing (a) crystalline and nanocrystalline phase, (b) nanocrystalline phase and (c) amorphous phase.

\subsubsection{X-ray Diffraction after Heat Treatment}

The study of the milled powders for $75 \mathrm{~h}$ has been completed with XRD analyses after heating at various temperatures. Samples have been heated to $300,500,650$ and $850{ }^{\circ} \mathrm{C}$ at $10{ }^{\circ} \mathrm{C} / \mathrm{min}$ and maintained at temperature for $1 \mathrm{~h}$, and after cooling, XRD have been performed at room temperature. As expected, up to $300{ }^{\circ} \mathrm{C}$ (Figure 9a,b) XRD does not show any significant structural change and no evidence of crystallisation is found. Between 500 and $650{ }^{\circ} \mathrm{C}$ (Figure $9 \mathrm{c}, \mathrm{d}$ ) the amorphous phase begins to crystallise giving rise to titanium aluminides such as $\mathrm{AlTi}, \mathrm{Al}_{3} \mathrm{Ti}$ and $\mathrm{AlTi}_{3}$ (Figure $9 \mathrm{~d}$ ), although the presence of Al crystals is also possible. This transformation of the amorphous to the crystalline phase can be confirmed in the diffraction pattern at $850{ }^{\circ} \mathrm{C}$ (Figure 9e), where all the main peaks are already well differentiated from each other. 


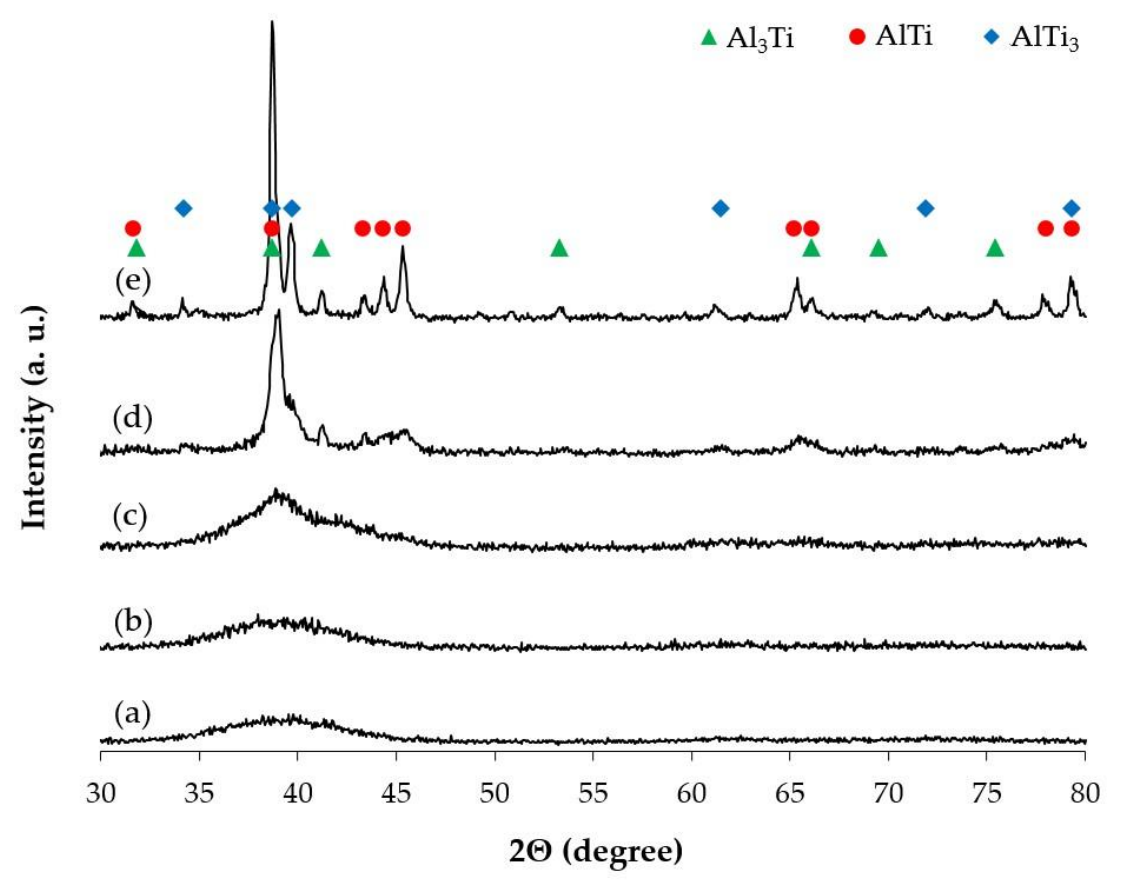

Figure 9. Room temperature $\mathrm{XRD}$ patterns of (a) the $\mathrm{Al}_{50} \mathrm{Ti}_{50}$ alloy milled for $75 \mathrm{~h}$, and heated to (b) 300, (c) 500, (d) 650 and (e) $850{ }^{\circ} \mathrm{C}$, after cooling.

\subsection{Electrical Resistance Sintering}

\subsubsection{Porosity}

At the beginning of the ERS process (pressing stage, at $80 \mathrm{MPa}$ ), the powder mass porosity decreases very little, both because of the high hardness of the amorphous powders and the low applied pressure. In general, after the whole process, amorphous powders milled for $75 \mathrm{~h}$ and ERS with low intensity still have a high porosity (Figure 10). For higher current intensities, the densification capacity increases. The increase in processing time (in cycles in Figure 10) acts in similar way.

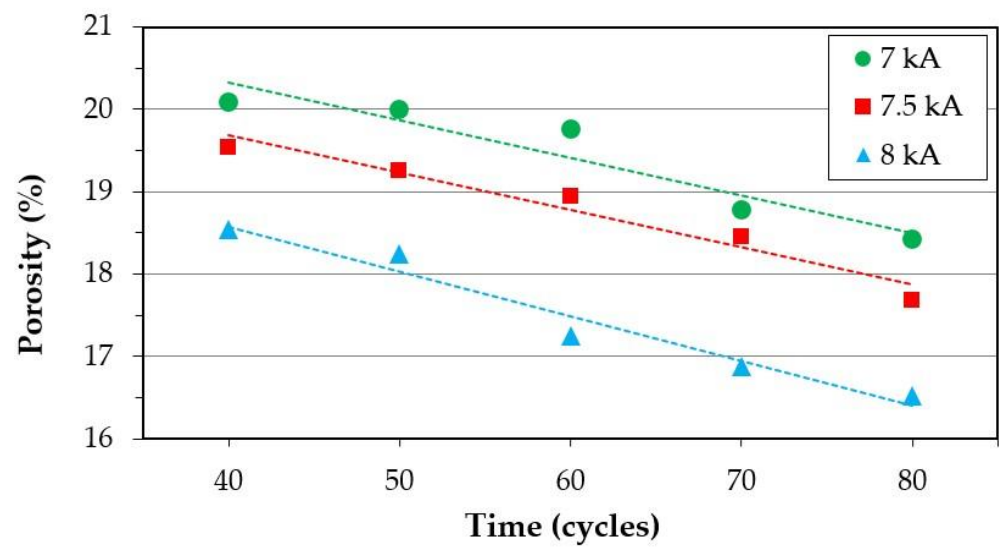

Figure 10. Final porosity vs. sintering time ( 50 cycles $=1 \mathrm{~s}$ ) of $\mathrm{Al}_{50} \mathrm{Ti}_{50}$ ERS compacts (from powder milled for $75 \mathrm{~h}$ ) for different current intensities.

No satisfactory experiments were carried out with current intensities lower than $7 \mathrm{kA}$ or higher than $8 \mathrm{kA}$. For low current intensities, the high electrical resistivity of the powder mass makes sintering difficult. For high current intensities, sintered compacts stick and cannot be separated of the wafers. As expected, it results difficult to remove the porosity of hardened amorphous powders after MA, however, this is not the case for softer unmilled crystalline powders. The porosity of ERS compacts 
made from pure Ti powders is much lower and can reach values of up to $4 \%$ even with lower current intensities (Figure 11).

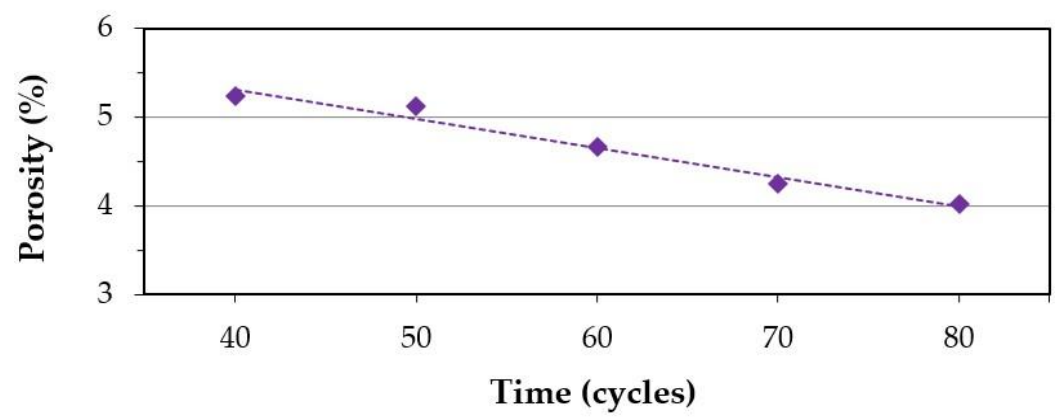

Figure 11. Final porosity vs. sintering time $(50$ cycles $=1 \mathrm{~s})$ of pure Ti ERS compacts (from unmilled powder) for $6 \mathrm{kA}$.

As observed in the trend lines in Figures 10 and 11, the slope for pure Ti compacts is smaller than in the case of milled $\mathrm{Al}_{50} \mathrm{Ti}_{50}$ compacts. Therefore, for ductile powders, the increase in sintering time does not affect the decrease in porosity as much as in the case of very hard powders.

The high-porosity ERS 7/40 Al-Ti compact (sintered with intensity of $7 \mathrm{kA}$ and 40 cycles) has been selected to show the effect of ERS on the microstructure (Figure 12). The uniform porosity distribution generally found in conventionally sintered compacts differs from the non-uniform distribution after ERS. Electrically sintered compacts have a more porous outer layer with a width of about $2 \mathrm{~mm}$ (Figure 12a,c) and a densified centre (Figure 12b,d). The ERS 7/40 compact has an average porosity of about $20.1 \%$, however, the porosity in the outer layer is about $32.8 \%$ and in the centre about $8.5 \%$. The porosity variation is caused by the unequal temperature distribution in the compact, consequence of the preferential electric paths inside the compact and the heat sink through the die walls. Temperature rises less and decreases faster near the wall of the ceramic die.

\subsubsection{X-ray Diffraction of Compacts after Heat Treatment}

An additional and important issue to consider is the effect of the sintering process on the microstructure. Although the sintering process is very quick, the temperature variation inside the compact could affect, as shown next, the stability of the amorphous phase. Also, the effect of additional exposure to high temperatures on the microstructure is of interest, because of the typical use of Al-Ti alloys [1].

The amorphous phase stability with temperature in the ERS 7/40 compact has been evaluated by XRD carried out at different temperatures (Figure 13). At room temperature (Figure 13a), after the ERS process, a small wide peak appears, due to the partial transformation of the amorphous phase into nanocrystals. Nanocrystals could probably be of $\mathrm{Al}$, or some of the intermetallic compounds AlTi, $\mathrm{Al}_{3} \mathrm{Ti}$ and $\mathrm{AlTi}_{3}$. If the compact is heated to $300^{\circ} \mathrm{C}$ (Figure 13b), the main peak (at $39^{\circ}$ ) starts growing, as a result of the increase of the crystalline phase. The peak still shows a significant width, typical of a small crystallite size. Although the temperature is not very high, the effect of time at this temperature (heating rate of $10^{\circ} \mathrm{C} / \mathrm{min}$ and $0.5 \mathrm{~h}$ at temperature) makes the amorphous structure to dissipate as compared with the sintered compact. At higher temperatures of 500 and $650{ }^{\circ} \mathrm{C}$ (Figure $13 \mathrm{c}, \mathrm{d}$ ) there is not a big difference between the main peaks, resulting a stable structure. 


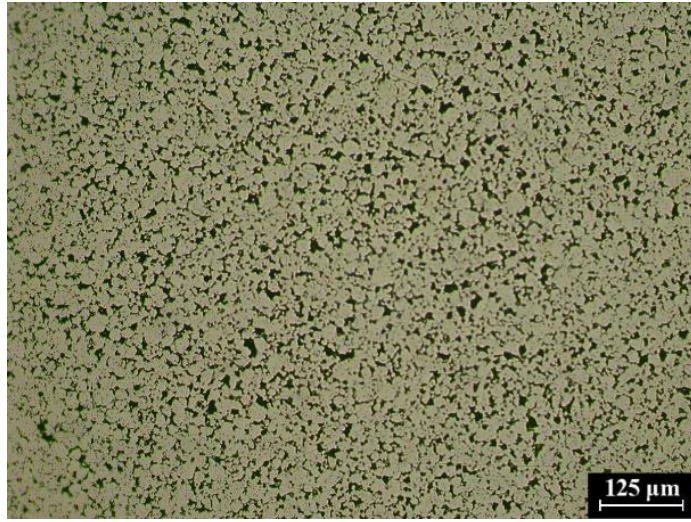

(a)

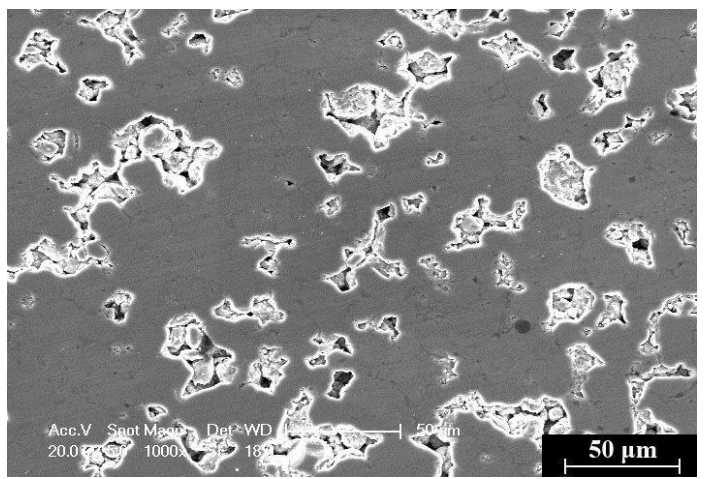

(c)

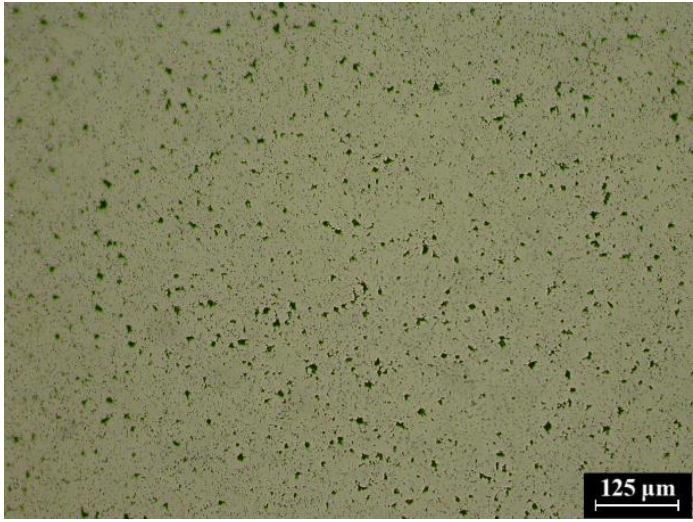

(b)

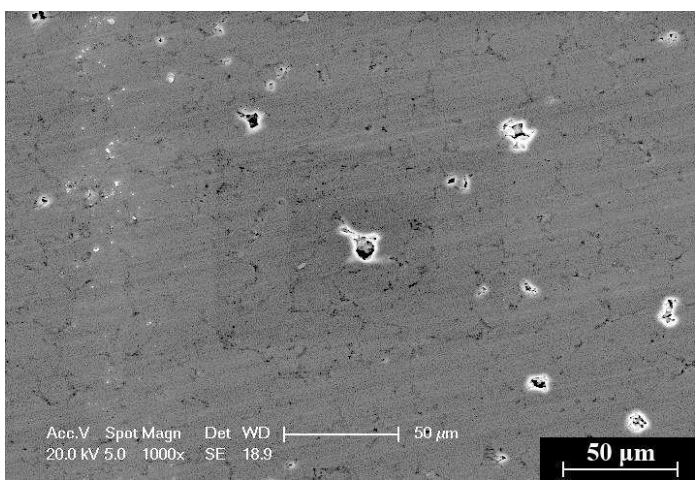

(d)

Figure 12. Distribution of porosity in the periphery $(\mathbf{a}, \mathbf{c})$ and core $(\mathbf{b}, \mathbf{d})$ of the ERS $7 / 40$ compact observed by optical microscopy $(\mathbf{a}, \mathbf{b})$ and SEM (c,d).

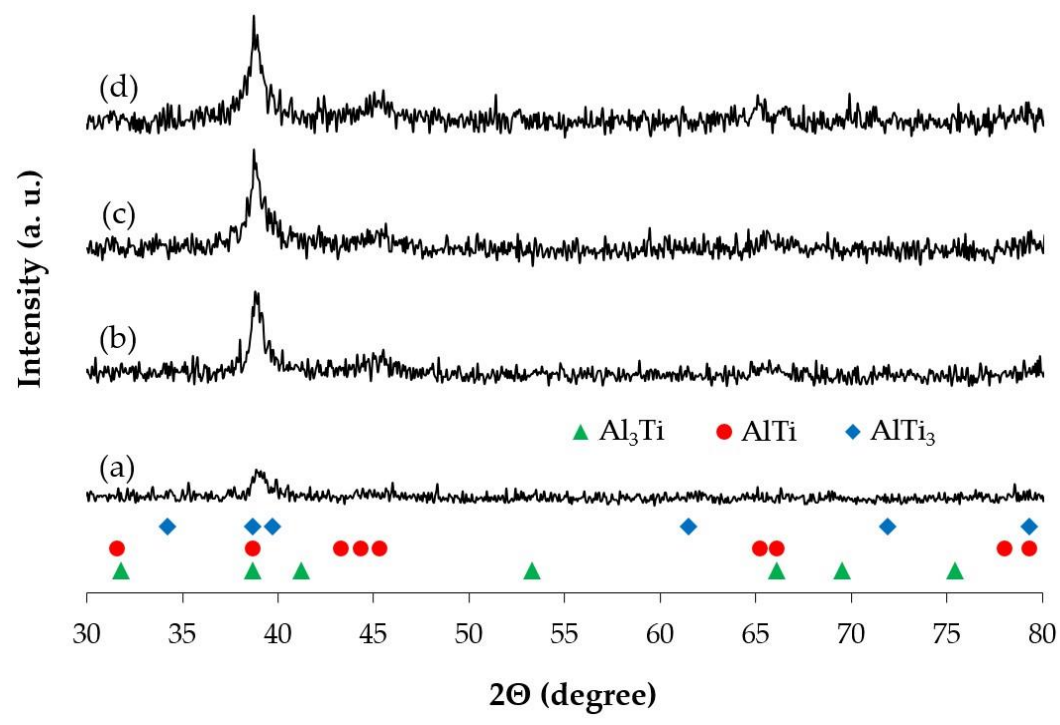

Figure 13. High temperature XRD patterns of ERS (7/40) $\mathrm{Al}_{50} \mathrm{Ti}_{50}$ compact heated up to (a) 25, (b) 300, (c) 500 and (d) $650{ }^{\circ} \mathrm{C}$.

\subsubsection{Hardness of Al-Ti Alloys}

The difference between the hardness of $\mathrm{Al}_{50} \mathrm{Ti}_{50}$ ERS compacts and that of other ones mentioned in the literature, prepared with similar procedures, has been studied. The hardness of the compacts, in general, depends mainly on two factors: the hardness of the powders that constitute the compact 
and the density of the resulting compact. Figure 14 shows the hardness values of some materials related to those studies.

First, the hardness values of the starting materials should be highlighted. Pure aluminium and titanium have a very low hardness compared to their alloys. Pure aluminium powder has a hardness of only $20 \mathrm{HV}$ [15]. This low hardness of the aluminium powder can be increased by mechanical alloying, both because of the grains refinement and by the effect of the PCA, leading to the formation of a solid solution, thus increasing the hardness of the powder to $127 \mathrm{HV}$ [16], which decreases after a short stress relieve treatment at $600{ }^{\circ} \mathrm{C}$ to $97 \mathrm{HV}$ [16]. In addition, after conventional consolidation by uniaxial pressing and furnace sintering the hardness of pure aluminium can decrease to $80 \mathrm{HV}$ [16], mainly because of the grain growth. It is also possible to increase the hardness of conventionally consolidated pure $\mathrm{Al}$ compacts to about $180 \mathrm{HV}$ by milling the powder in an atmosphere of ammonia $[17,18]$. Apart from grain refining, ammonia causes the formation of nitrogen-rich compounds that produce dispersion hardening.

Pure titanium has a higher hardness than pure aluminium. Commercial powders can reach up to about 70 HV [15] or 160 HV [19]. This difference depends largely on the morphology and/or fabrication process of the powder. On the other hand, pure titanium compacts can reach $255 \mathrm{HV}$ [20], $270 \mathrm{HV}$ [21] and $290 \mathrm{HV}$ [19].

In Al-Ti alloyed powder mixtures and compacts, there is a noticeable increase in hardness compared to pure Al. In general, a higher content of Ti produces a greater final hardness, because of forming an $\mathrm{Al}(\mathrm{Ti})$ solid solution after mechanical alloying and/or intermetallic compounds like $\mathrm{Al}_{3} \mathrm{Ti}, \mathrm{AlTi}$ and $\mathrm{AlTi}_{3}$ after heat treating or sintering. For instance, with the presence of only 2.88 at.\% of titanium, sintered aluminium compacts increase the hardness from $80 \mathrm{HV}$ to about $104 \mathrm{HV}$ [22]. With the increase of titanium up to 5.58 at.\%, the hardness increases to about $202 \mathrm{HV}$ [15]. In addition, for the $\mathrm{Al}_{50} \mathrm{Ti}_{50}$ alloy, the hardness increases to values between 300 and $790 \mathrm{HV}$ [23-28].

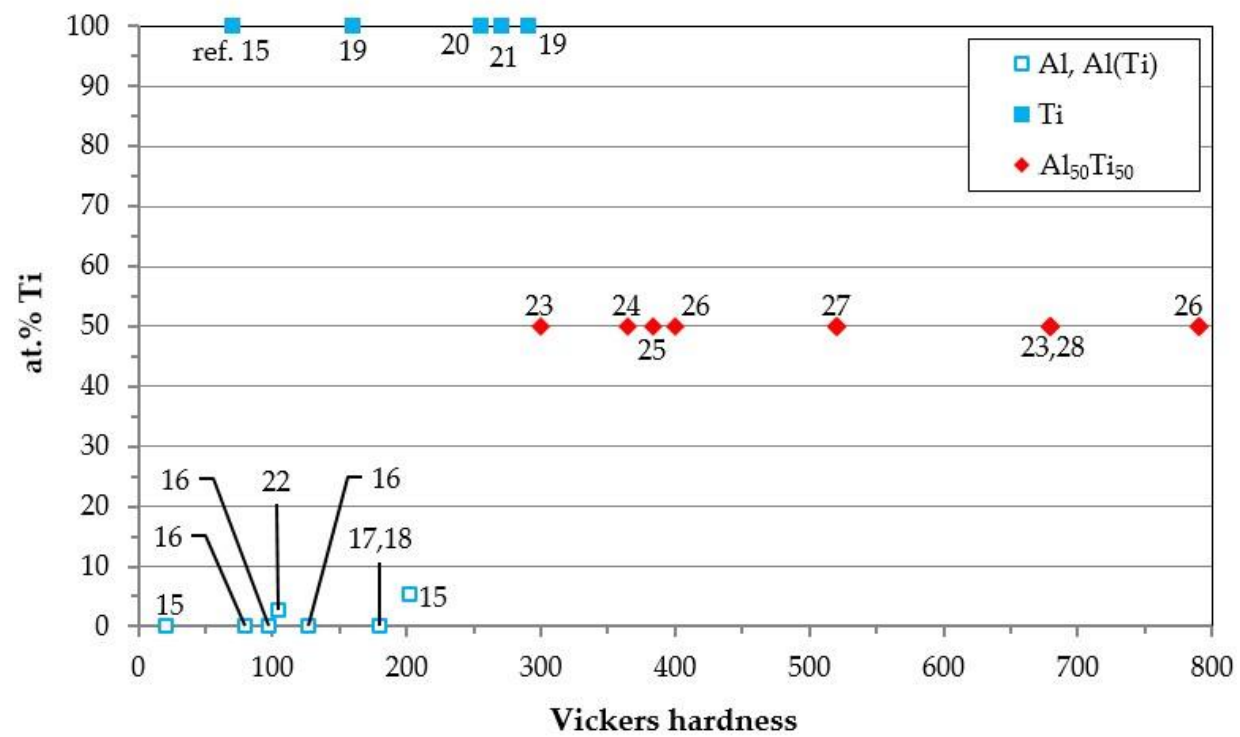

Figure 14. Hardness of aluminium, titanium and $\mathrm{Al}_{50} \mathrm{Ti}_{50}$ alloys according to bibliographic data [15-28].

The hardness results of the ERS compacts of this work are shown in Figure 15. Independently of the initial powder microstructure (crystalline or amorphous) current intensity has a similar effect on sintered compacts, with higher intensities resulting in higher hardness. However, the effect of sintering time does not have much influence on hardness, because the effect of time is lower on the energy transferred to the compact. In all the specimens, the centre $\left(\mathrm{HV}_{\mathrm{c}}\right)$ has a greater hardness than the outer layer $\left(\mathrm{HV}_{\mathrm{o}}\right)$. The hardness measured for the inner zone $\left(\mathrm{HV}_{\mathrm{i}}\right)$ does not show much difference with the centre hardness, since the porosity gradient is not uniform. There is a wide area around the 
compact centre with low and homogeneous porosity. Between the denser inner and the outer area, there is a sharp porosity change.
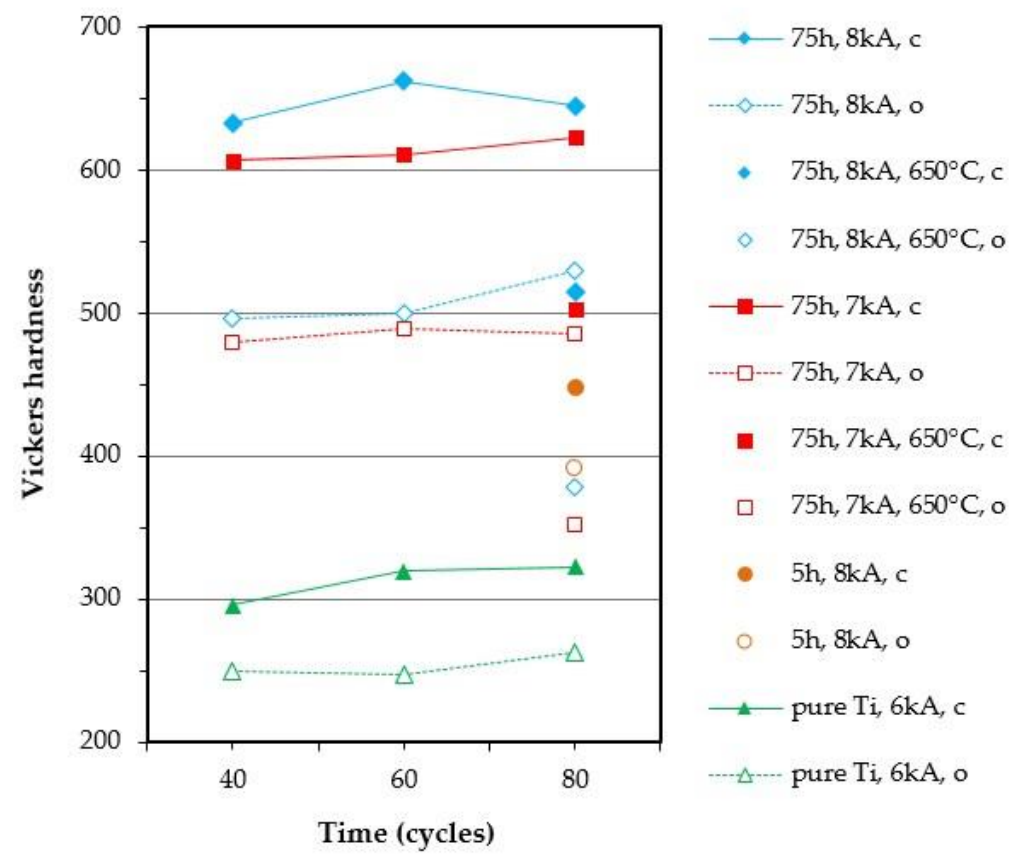

Figure 15. Hardness of ERS $\mathrm{Al}_{50} \mathrm{Ti}_{50}$ (and Ti for comparison) as-sintered and heat-treated compacts.

The highest measured hardness corresponds to the centre of the compact ERS at $8 \mathrm{kA}$ from amorphous powder milled for $75 \mathrm{~h}$. The microstructure contains mainly nanocrystals of aluminium and $\mathrm{Al}_{3} \mathrm{Ti}, \mathrm{AlTi}$ and $\mathrm{AlTi}_{3}$ compounds with possible amorphous phase residues. Vickers hardness reaches values between 633 and $662 \mathrm{HV}$ for different sintering times.

If lower current intensity $(7 \mathrm{kA})$ is applied, the hardness in the compact centre decreases slightly to values between 607 and $623 \mathrm{HV}$ because of the lower densification, although a higher amount of amorphous phase remains untransformed.

The hardness in the outer layer of the compact decreases considerably for both $8 \mathrm{kA}$ and $7 \mathrm{kA}$. Hardness values vary between 480 and $530 \mathrm{HV}$. The prevalence of an amorphous structure in this area because of the lower attained temperature, versus a nanocrystalline or crystalline structure development, should account for a higher hardness. However, the predominant factor is the increase in porosity, negatively affecting hardness.

After an annealing heat treatment (for 7 and $8 \mathrm{kA}$ ERS compact) up to $650{ }^{\circ} \mathrm{C}$ for $1 \mathrm{~h}$, the hardness decreases considerably. In the centre, the hardness reaches 503-515 HV, with values between 352-378 HV in the outer porous layer. This decrease of around $20 \%$ is due to the amorphous/nanocrystalline to crystalline phase transformation and grain growth.

For ERS compacts prepared from Al-Ti powder milled for $5 \mathrm{~h}$, the hardness reaches values between 392 and $448 \mathrm{HV}$ in the inner and periphery, respectively. After $5 \mathrm{~h}$ of milling, the powder microstructure has not reached an amorphous structure, but a supersaturated solid solution with areas of aluminium and titanium. After ERS processing with $8 \mathrm{kA}$, the microstructure will probably consist in a small percentage of intermetallic compounds together with solid solutions and pure elements.

Finally, it has been confirmed that the hardness of the ERS 6/40-80 pure Ti compacts (both in the centre and periphery) is lower than that of the compacts prepared from milled $\mathrm{Al}_{50} \mathrm{Ti}_{50}$ powders. Hardness ranges between 248-263 HV for the outer layer and 296-323 HV for the centre of the compact. These compacts are highly densified, but no hardening mechanism is developed for pure titanium. 


\section{Conclusions}

A novel method of compacts processing of the $\mathrm{Al}_{50} \mathrm{Ti}_{50}$ alloy obtained by mechanical alloying and subsequent consolidation by ERS has been investigated. As expected, amorphous and/or nanocrystalline, powders of the $\mathrm{Al}_{50} \mathrm{Ti}_{50}$ alloy were prepared by mechanical alloying up to $75 \mathrm{~h}$. Particles size of the powders reached about $8.6 \mu \mathrm{m}$ and showed an almost spherical shape. It has been checked that the amorphous phase crystallizes at about $500{ }^{\circ} \mathrm{C}$, forming titanium aluminides.

Amorphous and/or nanocrystalline powders of the $\mathrm{Al}_{50} \mathrm{Ti}_{50}$ alloy were successfully sintered by ERS with different current intensities $(7-8 \mathrm{kA})$ and processing times $(0.8-1.6 \mathrm{~s})$. This technique avoids the difficulty of obtaining a green compact for conventional sintering because of the high hardness of these compacts. Electrically sintered compacts show non-uniform distribution of porosity with a porous outer layer and densified centre. For instance, the ERS 7/40 compact has a global porosity of about $20.1 \%$, however, the porosity in the outer layer is about $32.8 \%$ and in the centre about $8.5 \%$. The electrically sintered compact processed with $8 \mathrm{kA}$ for $1.2 \mathrm{~s}$ from amorphous powders reaches a significant Vickers hardness of up to 662 HV.

Author Contributions: Conceptualization, P.U., J.M.M. and F.G.C.; methodology, J.M.M. and F.G.C.; validation, P.U., F.T., E.S.C. and S.N.; writing—original draft, P.U.; writing—review \& editing, P.U., F.T., E.S.C., S.N., J.M.M. and F.G.C.

Funding: This research was funded by Ministerio de Economía y Competitividad (Spain) and Feder (EU) through the research projects DPI2015-69550-C2-1-P and DPI2015-69550-C2-2-P.

Acknowledgments: The authors also wish to thank the technicians J. Pinto, M. Madrid and M. Sánchez (University of Seville, Spain) for experimental assistance.

Conflicts of Interest: The authors declare no conflict of interest.

\section{References}

1. Appel, F.; Clemens, H.; Fischer, F.D. Modeling concepts for intermetallic titanium aluminides. Prog. Mater. Sci. 2016, 81, 55-124. [CrossRef]

2. Appel, F.; Wagner, R. Intermetallics: Titanium aluminides. In Encyclopedia of Materials: Science and Technology, 2nd ed.; Elsevier Science \& Technology: London, UK, 2001; pp. 4246-4264.

3. Xia, Z.H.; Zhang, M.; Zhang, Y.; Zhao, Y.; Liaw, P.K.; Qiao, J.W. Effects of Ni-P amorphous films on mechanical and corrosion properties of $\mathrm{Al}_{0.3} \mathrm{CoCrFeNi}$ high-entropy alloys. Prog. Mater. Sci. 2019, 104, 250-329.

4. Krasnowski, M.; Kulik, T. Nanocrystalline or amorphous matrix $\mathrm{Al}_{60} \mathrm{Fe}_{15} \mathrm{Ti}_{15}(\mathrm{Co} / \mathrm{Mg} / \mathrm{Zr})_{5}-5 \% \mathrm{~B}$ composites produced by consolidation of mechanically alloyed powders-lightweight materials with high hardness. Intermetallics 2012, 28, 120-127. [CrossRef]

5. Qiao, J.C.; Wang, Q.; Pelletier, J.M.; Kato, H.; Casalini, R.; Crespo, D.; Pineda, E.; Yao, Y.; Yang, Y. Structural heterogeneities and mechanical behavior of amorphous alloys. Intermetallics 2018, 94, 65-72. [CrossRef]

6. Olevsky, E.A.; Dudina, D.V. Field-Assisted Sintering, Science and Applications; Springer: Cham, Switzerland, 2018.

7. Olevsky, E.A. Spark-Plasma Sintering and Related Field-Assisted Powder Consolidation Technologies; MDPI Books: Basel, Switzerland, 2017.

8. Maurya, R.S.; Sahu, A.; Laha, T. Quantitative phase analysis in $\mathrm{Al}_{86} \mathrm{Ni}_{8} \mathrm{Y}_{6}$ bulk glassy alloy synthesized by consolidating mechanically alloyed amorphous powder via spark plasma sintering. Mater. Des. 2016, 93, 96-103. [CrossRef]

9. Maurya, R.S.; Sahu, A.; Laha, T. Effect of consolidation pressure on phase evolution during sintering of mechanically alloyed Al86Ni8Y6 amorphous powders via spark plasma sintering. Mater. Sci. Eng. A 2016, 649, 48-56. [CrossRef]

10. Lux, J. For an Improved Manufacture of Electric Incandescent Lamp Filaments from Tungsten or Molybdenum or an Alloy Thereof. Great Britain Patent No. 27002, 13 December 1906.

11. Weintraub, G.; Rush, H. Process and Apparatus for Sintering Refractory Materials. U.S. Patent No. 1071488A, 26 August 1913.

12. Taylor, G.F. Apparatus for Making Hard Metal Compositions. U.S. Patent No. 1896854, 7 February 1933. 
13. Gallardo, J.M.; Agote, I.; Astacio, R.; Schubert, T.; Cintas, J.; Montes, J.M.; Torres, Y.; Cuevas, F.G. Hard metal production by ERS: Processing parameters role in final properties. Metals 2019, 9, 172. [CrossRef]

14. Montes, J.M.; Gómez Cuevas, F.; Ternero, F.; Astacio, R.; Sánchez Caballero, E.; Cintas, J. Medium-frequency electrical resistance sintering of oxidized C.P. iron powder. Metals 2018, 8, 426. [CrossRef]

15. Cuevas, F.G.; Cintas, J.; Montes, J.M.; Gallardo, J.M. Al-Ti powder produced through mechanical alloying for different times. J. Mater. Sci. 2006, 41, 8339-8346. [CrossRef]

16. Cintas, J.; Rodríguez, J.A.; Gallardo, J.M.; Herrera, E.J. Simplification of the processing of milled aluminium powder and mechanical properties evaluation. Rev. Metal. 2001, 37, 370-375. [CrossRef]

17. Caballero, E.S.; Cintas, J.; Cuevas, F.G.; Montes, J.M.; Herrera-García, M. Improvement in the mechanical behavior of mechanically alloyed aluminum using short-time $\mathrm{NH}_{3}$ flow. Metall. Mater. Trans. A 2016, 47, 6481-6486. [CrossRef]

18. Cintas, J.; Cuevas, F.G.; Montes, J.M.; Herrera, E.J. High-strength PM aluminium by milling in ammonia gas and sintering. Scr. Mater. 2005, 53, 1165-1170. [CrossRef]

19. Ohno, T.; Kubota, M. Effect of mechanical milling atmosphere on hardness and constituent phase of pure titanium. J. Jpn. Inst. Light Met. 2010, 60, 647-653. [CrossRef]

20. Kao, Y.L.; Tu, G.C.; Huang, C.A.; Liu, T.T. A study on the hardness variation of $\alpha$ - and $\beta$-pure titanium with different grain sizes. Mater. Sci. Eng. 2005, 398, 93-98. [CrossRef]

21. Poondla, N.; Srivatsan, T.S.; Patnaik, A.; Petraroli, M. A study of the microstructure and hardness of two titanium alloys: Commercially pure and Ti-6Al-4V. J. Alloy. Compd. 2009, 486, 162-167. [CrossRef]

22. Cuevas, F.G.; Cintas, J.; Rodríguez, J.A.; Gallardo, J.M. Structure and Properties of consolidated attrition-milled Al-5\%Ti PM specimens. Mater. Sci. Forum 2003, 426-432, 4307-4312. [CrossRef]

23. Weisheit, A.; Mordike, B.L.; Smarsly, W.; Richter, K.H. Laser surface remelting and laser surface gas alloying of an intermetallic TiAl alloy. Lasers Eng. 2000, 10, 63-81.

24. Sahu, P. Lattice imperfections in intermetallic Ti-Al alloys: An X-ray diffraction study of the microstructure by the Rietveld method. Intermetallics 2006, 14, 180-188. [CrossRef]

25. Adams, A.G.; Rahaman, M.N.; Dutton, R.E. Microstructure of dense thin sheets of $\gamma$-TiAl fabricated by hot isostatic pressing of tape-cast monotapes. Mater. Sci. Eng. 2008, 477, 137-144. [CrossRef]

26. Itsukaichi, T.; Masuyama, K.; Umenoto, M.; Okane, I. Mechanical alloying of Al-Ti powder mixtures and their subsequent consolidation. J. Mater. Res. 1993, 8, 1817-1828. [CrossRef]

27. Takekazu, N.; Shigeoki, S.; Takashi, Y.; Masateru, N.; Masaru, Y. Preparation of functionally graded materials by pulse current pressure sintering of ball milled Al-50 at\%Ti powder. Mater. Trans. JIM 2000, 41, 457-460.

28. Samsonov, G.V.; Vinnitsky, I.M. Refractory Compounds, A Reference Book, 2nd ed.; Metallurgiya: Moscow, Russia, 1976; pp. 300-307. 